\title{
The Crustal Thickness of the Philippine Sea Plate Derived from Gravity Data
}

\author{
Horng-Yuan Yen ${ }^{1, *}$, Yu-Tsung Lo ${ }^{1}$, Yu-Lien Yeh ${ }^{2}$, Hsien-Hsiang Hsieh ${ }^{3}$, Wen-Yen Chang ${ }^{4}$, \\ Chieh-Hung Chen ${ }^{2}$, Chun-Rong Chen ${ }^{1}$, and Min-Hung Shih ${ }^{1,3}$ \\ ${ }^{I}$ Department of Earth Sciences, National Central University, Chung-Li, Taiwan, R.O.C. \\ ${ }^{2}$ Department of Earth and Environmental Sciences, National Chung Cheng University, Chiayi, Taiwan, R.O.C. \\ ${ }^{3}$ Institute of Earth Sciences, Academia Sinica, Taipei, Taiwan, R.O.C. \\ ${ }^{4}$ Department of Natural Resources and Environmental Studies, National Dong-Hwa University, Hualien, Taiwan, R.O.C.
}

Received 24 April 2014, revised 16 November 2014, accepted 17 November 2014

\begin{abstract}
We constructed a new free-air gravity anomaly map of the Philippine Sea Plate (PSP) using ship-tracked gravity data from the National Geophysical Data Center (NGDC). Our results show that the isogals trend correlates well with the tectonic structures in the PSP. After removing the gravity induced by sea water from the free-air gravity data, we obtained the regional Bouguer gravity anomaly, which is later used to compute the Moho geometry in the PSP by applying the Parker-Oldenburg iterative method. Our results indicate that in the southern part of the West Philippine Basin (WPB) the crustal thickness is nearly homogeneous with a value of about $5 \mathrm{~km}$, which implies that the WPB is quite stable. The low-amplitude and near-zero free-air gravity anomalies clearly indicate that the whole WPB, except at trenches and island arcs, is nearly in a state of isostatic equilibrium. The average crustal thickness of the Palau Kyushu Ridge (PKR) is more than $10 \mathrm{~km}$. In the eastern PSP the crustal thickness gradually increases eastward. Our results also imply that a relatively thin and low density mantle exists beneath the Parece Vela Basin (PVB) as a consequence of back-arc spreading and serpentinized upwells of the thin crustal thickness.
\end{abstract}

Key words: Free-air gravity anomaly, Bouguer gravity anomaly, Crustal thickness, Philippine Sea Plate, Mantle upwelling

Citation: Yen, H. Y., Y.T.Lo, Y.L.Yeh, H. H. Hsieh, W. Y. Chang, C. H. Chen, C. R. Chen, and M. H. Shih, 2015: The crustal thickness of the Philippine Sea Plate derived from gravity data. Terr. Atmos. Ocean. Sci., 26, 253-259, doi: 10.3319/TAO.2014.11.17.01(T)

\section{INTRODUCTION}

The Philippine Sea Plate (PSP) is located in the western Pacific Ocean, bounded by the Pacific and Eurasian plates and within the latitude range $5-35^{\circ} \mathrm{N}$ and longitude range $120-150^{\circ} \mathrm{E}$ (Fig. 1). The PSP is also surrounded by convergent boundaries. Four subduction zones lie along the eastern PSP: the Izu-Bonin Trench (IBT), the Mariana Trench (MT), the Yap Trench (YT) and the Palau Trench (PAT) stretching from north to south. There are also four subduction zones along the western PSP, which include the Philippine Trench (PT), the Manila Trench (MAT), the Ryukyu Trench (RT) and the Nankai Trough (NT). The interior of the PSP can be divided into three major basins: the Shikoku Basin (SB), the Parece Vela Basin (PVB) and the West Philippine Basin (WPB). Another prominent geological feature is the Palau Kyushu Ridge (PKR) with North-South trending (Fig. 1).

\footnotetext{
* Corresponding author

E-mail:yenhy@earth.ncu.edu.tw
}

Several bathymetric features within the WPB include the NW-SE striking Central Basin Fault (CF), the Daito Ridge (DR) and the Oki-Daito Ridge (ODR).

Investigating the tectonic significances in the PSP has been a challenge for the past few decades because the PSP has complex geological structures such as basins caused by back-arc spreading and ridges and is also surrounded by an active plate collision boundary with trenches and volcanic arcs. Many geological and geophysical investigations into the PSP have been reported (Seekins and Teng 1977; Seno and Maruyama 1984; Yu and Chang 1991; Oda and Senna 1994; Hall et al. 1995; Nakamura and Shibutani 1998; Okino et al. 1998, 1999; Yang and Wang 1998; Fujioka et al. 1999; Yu et al. 2000; Kamimura et al. 2002; Okino and Fujioka 2003; Ohara 2006; Chang et al. 2007; Ishihara and Koda 2007; Nishizawa et al. 2007, 2011; Isse et al. 2009; Yeh et al. 2013). These previous studies suggested that different tectonic/geological structures show distinct velocity structures. However, most of these studies focused on the physical properties of the 
lithospheric structure and its evolution, with the PSP crustal structures remaining unclear or unsolved. The other limitation in seismological research is that the uneven distribution of earthquakes and monitoring stations may cause certain regions in the PSP to have less resolution. In order to overcome the above mentioned problems, we intend to use gravity data that is more evenly distributed than seismic data. This provides us with the opportunity to explore the PSP crust characteristics, such as the Moho geometry using only essential gravity data. Ishihara and Koda (2007) used the marine gravity data in the northern and central Philippine Sea to calculate the crustal thickness by applying three-dimensional gravity modeling. In this study we construct a new free-air, Bouguer gravity anomaly map for the whole PSP region. Our goal is to investigate first order features of the crustal structure. For this purpose we assume that the gravity anomaly comes solely from the density contrast between the crust and the mantle. With this assumption we are able to derive the undulation of the Moho depth. The Moho depth in the PSP area is derived from a newly integrated gravity data set by executing a MATLAB source code "3DINVER.M" (Gómez-Ortiz and Agarwal 2005). Our results provide us with new insight into the crustal thickness beneath the PSP.

\section{DATA COMPILATION AND THE BOUGUER ANOMALY MAP}

Gravity measurements and analyses are particularly useful for the reconnaissance of a large tectonic region. A high resolution gravity map of the PSP can help us understand its tectonic significance. The free-air anomaly data collected in this study from 365 cruises in the PSP are compiled from the National Geophysical Data Center (NGDC) archive maintained by the National Oceanic Atmospheric Administration (NOAA), USA. These data sets were calibrated using the International Gravity Standardization Net 1971 and the gravity anomaly was referenced to the Geodetic Reference System 1967.

The compiled new free-air anomaly map of the PSP is shown in Fig. 2. Most parts of the PSP have low-amplitude ( $\pm 50 \mathrm{mgal})$, long-wavelength free-air anomalies with nearzero average values. The trend of the isogals correlates well with the geological structures as well as with the bathymetry of the PSP. For example, positive anomalies, generally with a high frequency, are observed with islands, seamounts, and ridges. Large free-air anomalies often occur in the active volcanoes on the ridges. The highest free-air anomaly is in Chichishima, located in the Bonin Islands with a maximum value of $380 \mathrm{mgal}$. The most prominent large-amplitude, short-wavelength negative lineation occurs at the trenches. The lowest free-air anomaly is located at the tip of the MT with a minimum value of $-350 \mathrm{mgal}$. These anomalies may be the result of oceanic slab subsidence having thick sediments.

The complexity of the gravity anomalies appears to differ greatly between the eastern and western sides of the PKR. This difference may be caused by a difference in the mean depths and the bathymetry of the eastern and western Philippine basin. It is worth noting that around the seamounts, large and narrow bands of positive anomalies neighbor wide negative anomalies, similar to the dipoletype magnetic anomalies.

The fact that free-air anomalies are generally small over the Earth's surface is explained by the fact that the Earth's crust is nearly in isostatic equilibrium (Bowin et al. 1982). Thus, the near-zero anomaly over the PSP (Fig. 2), with the exception of trenches and island arc regions, clearly indicates that the PSP is essentially in isostatic equilibrium.

We replaced sea water (density: $1.03 \mathrm{~g} \mathrm{~cm}^{-3}$ ) with oceanic crust (density: $2.9 \mathrm{~g} \mathrm{~cm}^{-3}$ ) using a simple integration process to construct the Bouguer anomaly map of the PSP (Lowrie 2007). The terrain correction for the seabed topography can be ignored for large-scale investigations. The Bouguer anomaly map (Fig. 3) shows that, in general, isogals agree well with the overall structural trend of the PSP. It can be seen that the Bouguer anomalies distribution is smooth over most of the PSP, with values of about 300 mgal. The exceptions, however, are locations like trenches, rising ridges, and island arcs. In general, large positive Bouguer anomalies are

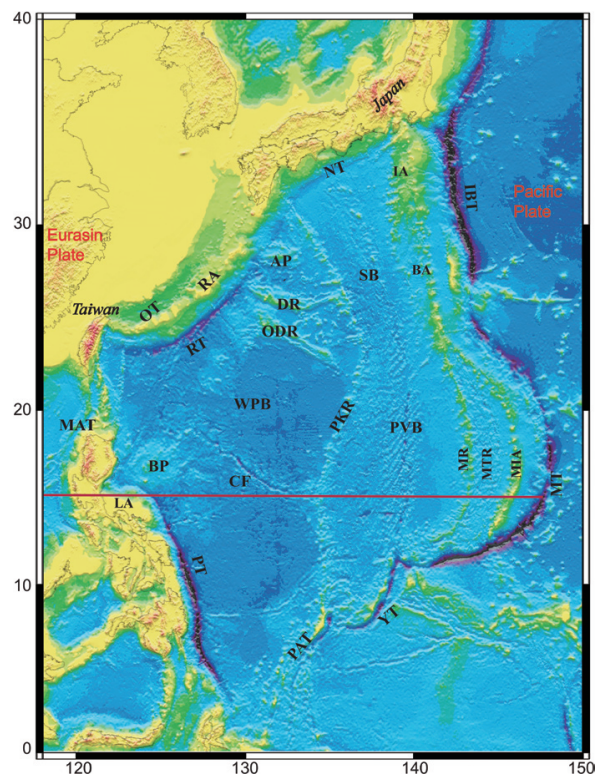

Fig. 1. Map showing the bathymetry and major tectonic structures of the Philippine Sea Plate (PSP). AP: Amani Plateau; BP: Benham Plateau; BA: Bonin Arc; CF: Central Basin Fault; DR: Daito Ridge; IA: Izu Arc; IBT: Izu-Bonin Trench; LA: Luzon Arc; MAT: Manila Trench; MIA: Mariana Island Arc; MR: Mariana Ridge; MT: Mariana Trench; MTR: Mariana Trough; NT: Nankai Trough; ODR: OkiDaito Ridge; OT: Okinawa Trough; PKR: Palau Kyushu Ridge; PT: Philippine Trench; PAT: Palau Trench; PVB: Parece Vela Basin; RA: Ryukyu Arc; RT: Ryukyu Trench; SB: Shikoku Basin; WPB: West Philippine Basin; YT: Yap Trench; respectively. The Chichishima, as part of the Bonin Islands is marked by the red solid triangle. The red thick line indicates the cross-section shown in Figs. 5 and 6. 


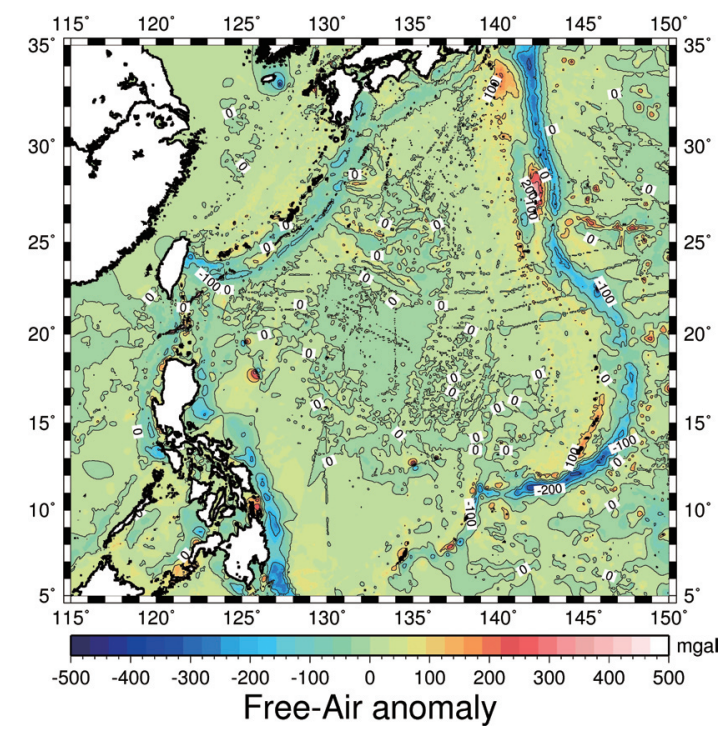

Fig. 2. Free-air anomaly map of the PSP with a 50 mgal contour interval. Low-amplitude, long-wavelength free-air anomalies, near-zero average values between 50 and $-50 \mathrm{mgal}$, cover an overwhelming part of the PSP. The isogals trend generally in consonance with the overall geological units and correlate closely with the variations in seabed topography of the PSP.

found in regions where the crust is very thin (Lowrie 2007). The Bouguer gravity anomalies in the southern part of the WPB with values larger than +400 mgal are somewhat higher than those in the northern part. Low Bouguer anomalies (smaller than $300 \mathrm{mgal}$ ) are found in the Amani Plateau (AP), the DR and the ODR. The Bouguer gravity anomaly clearly shows significant differences between the eastern and western PSP. The eastern PSP gravity anomaly ranges between 350 - 400 mgal. Linear Bouguer anomalies, ranging from 200 - 300 mgal, are found in the PKR, the Izu Arc (IA), the Bonin Arc (BA), the Mariana Ridge (MR), and the Mariana Island Arc (MIA). Along the Philippine and Ryukyu trench systems, the Bouguer gravity anomaly has a low value, ranging between 100 - $200 \mathrm{mgal}$ and a high gradient.

We applied the upward continuation algorithm (Vasin et al. 1996; Martyshko and Prutkin 2003) to obtain the regional Bouguer anomaly induced from the relief of the crust-mantle boundary. This algorithm can suppress the short-wavelength gravity effects due to the incomplete removal of the bathymetric effect during the Bouguer correction process. In other words, the procedure allows us to eliminate the effect of shallow anomalous masses. Following the algorithmic procedure noted above, the regional Bouguer map (Fig. 3) corresponding to gravitational effects below a depth of $10 \mathrm{~km}$ is constructed. This is used to compute the variations of the Moho depth in the PSP and its surrounding area.

\section{METHODOLOGY}

We adapted the code developed by Gómez-Ortiz and

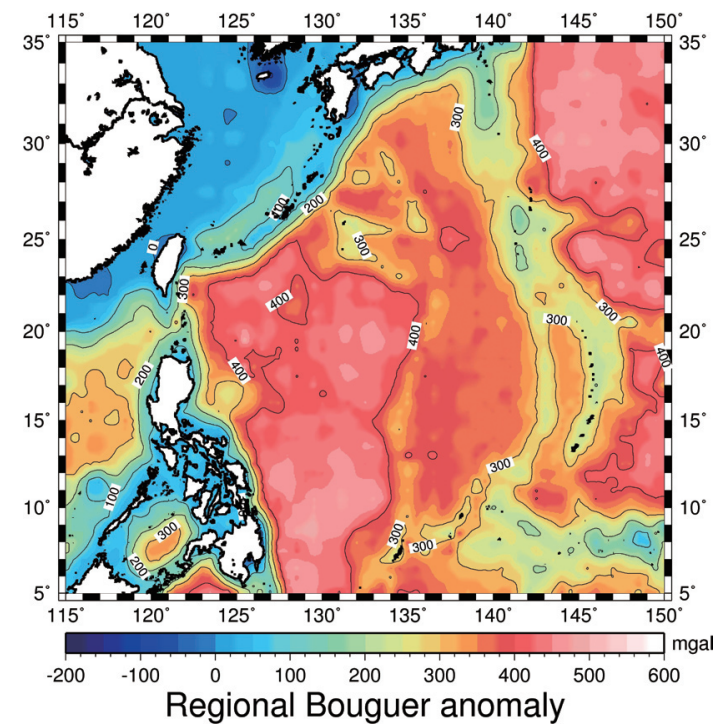

Fig. 3. The regional Bouguer gravity anomaly map was obtained after replacing the sea-water layer to the crust. The contour interval is $100 \mathrm{mgal}$.
Agarwal (2005) that adapted the Parker-Oldenburg method for computing the 3D geometry of the density interface from a gridded gravity anomaly data set. The procedure described by Parker (1973) is used to calculate the gravity anomaly induced from two homogeneous layers with different densities and an uneven boundary, and is given by the following equation:

$F(\Delta g)=-2 \pi G \rho e^{\left(-k z_{0}\right)} \sum_{n=1}^{\infty} \frac{k^{n-1}}{n !} F\left[h^{n}(x)\right]$

where $F(\Delta g)$ is the Fourier transform of the gravity anomaly, $G$ is the universal gravitational constant, $\rho$ is the density contrast across the interface, $k$ is the wave number, $h(x)$ is the depth to the interface (positive downwards), and $z_{0}$ is the average depth of the horizontal interface.

We compute the undulating interface depth from gravity anomaly data following Oldenburg (1974) by rearranging Eq. (1):

$F[h(x)]=-\frac{F[\Delta g(x)] e^{\left(k z_{0}\right)}}{2 \pi G \rho}-\sum_{n=2}^{\infty} \frac{k^{n-1}}{n !} F\left[h^{n}(x)\right]$

The first term in Eq. (2) is obtained by setting $h(x)=0$ (Oldenburg 1974) and the first approximate value $h(x)$ is obtained by taking its inverse Fourier transform. The value of $h(x)$ is iteratively calculated in Eq. (2) to estimate a new one until a reasonable solution is achieved. Because the Parker-Oldenburg method is unstable at high wavenumbers, Gómez-Ortiz and Agarwal (2005) added a cosine low-pass filter to filter 
out high-wavenumber signals. We set $0.012 \mathrm{~km}^{-1}$ as the cutoff wavenumber to process the gravity anomaly data.

The above algorithm is applied to compute the Moho depth in the PSP and its surrounding area $\left(7-33^{\circ} \mathrm{N}\right.$ and $117-148^{\circ} \mathrm{E}$ ) from the regional Bouguer gravity anomaly (Fig. 3) with a grid spacing of $20 \mathrm{~km}$. We assumed that the average Moho depth is $20 \mathrm{~km}$, which is in good agreement with previous studies (Mooney et al. 1998, Kamimura et al. 2002; Kodaira et al. 2007). The common density contrast is set equal to $0.4 \mathrm{~g} \mathrm{~cm}^{-3}$ between the crust and the mantle, which is also applied.

\section{CRUSTAL THICKNESS AND DISCUSSIONS}

\subsection{Crustal Thickness in the PSP}

Iterative procedure convergence was achieved at the $8^{\text {th }}$ iteration with an RMS error of $0.017 \mathrm{~km}$. This RMS error is comparable to the RMS error of $0.0147 \mathrm{~km}$ obtained from the study of Gómez-Ortiz and Agarwal (2005), which implies that the inversion result is reasonable. Additionally, the largest difference between the observed and calculated regional gravity anomaly ranges between $0 \sim-5$ mgal (using the forward modeling algorithm). This misfit is reasonable for gravity inversion. Hence, the Moho depth derived by this study the PSP region is reliable.

The PSP crustal thickness can be obtained by subtracting the sea water depth from the Moho depth (Fig. 4). The PSP crustal thickness that we derived also agrees well with the overall geological features. For most parts of the WPB, which is the oldest unit among the PSP, the average crustal thickness is about $5 \mathrm{~km}$, which implies that the WPB is a typically stable oceanic crust. The relatively thick crust is found beneath the DR, ODR, AP, and the Benham Plateau (BP), with crustal thickness ranging from $10-15 \mathrm{~km}$. The crust thickens rapidly towards the Ryukyu Arc (RA), the Luzon Arc (LA), and the passive continental margin. The increase in crustal thickness in these areas is a result of transition from oceanic to continental crust. The crustal thickness of the PKR increases gradually from south to north with an average thickness of more than $10 \mathrm{~km}$.

The crustal thickness (Fig. 4) shows a N-S trend, which is nearly perpendicular to the relative motion between the PSP and the Pacific plate, and is consistent with the strike of the regional structures in the eastern PSP. The crustal thickness beneath the SB and the PVB is, on average, less than $10 \mathrm{~km}$, and is greater than what it is in the WPB. The thinnest crust is observed in the southern part and at the western margin of the SB with a thickness of approximately $5 \mathrm{~km}$. This is consistent with previous studies using the seismic method (Nishizawa et al. 2011). The crust thinness implies that this basin might have been formed during the initial rifting and spreading stages (Nishizawa et al. 2011). The crustal thickness increases gradually eastwards reaching values between $15-20 \mathrm{~km}$ in the IA and the BA.
The crustal thickness is about $8 \mathrm{~km}$ in the central PVB and thickens away from the central part. In comparison, the crustal thickness beneath the PVB, based on seismic refraction profiles, is only $5 \mathrm{~km}$ (Nishizawa et al. 2007), which is smaller than the value obtained in our results. Ishihara and Koda (2007) conducted 3D gravity modeling and obtained the same crustal thickness we derived in the northwestern and northeastern parts of the PVB. As the Bouguer anomaly distributions (Fig. 3) clearly show there is a prominent difference between the WPB (larger than $400 \mathrm{mgal}$ ) and the eastern Philippines, including the SB and the PVB (350 - 400 mgal). It is interesting to understand why the same crustal thickness existing beneath the WPB and the PVB corresponds to different Bouguer anomalies. Although the variation in crustal thickness is often considered as one of the primary factors responsible for the distinct Bouguer anomaly in this case, there must be other factors that result in changes in gravity without a significant crustal thickness change. Ishihara and Koda (2007) speculated that the lower Bouguer anomaly accompanying the thin crust in the PVB is caused by the upwelling asthenosphere (low density compared to the lithosphere) and the serpentinized mantle. We shall discuss the issue more in detail in the section 4.3.

Our results also suggest that the crustal thickness is 15 $18 \mathrm{~km}$ in the MR, $12-15 \mathrm{~km}$ in the Mariana Trough (MTR) and about $20 \mathrm{~km}$ underneath the MIA. We also found that the crustal thickness increases towards the active margin of the eastern PSP, which indicates that the crust is undergoing great deformation.

\subsection{Gravity Anomalies and the Profile of Crustal Thickness Along $15^{\circ} \mathrm{N}$}

Figure 5 illustrates the lateral variations in crustal thickness and its correlation with gravity anomalies along $15^{\circ} \mathrm{N}$. This transect is across the LA, PT, WPB, PKR, PVB, MR, MTR, and the MIA, and ends up on the eastern side of the MT. In the westernmost section the most prominent feature is the presence of very low Bouguer anomalies (near zero mgal) in the LA with a crustal thickness of $33 \mathrm{~km}$. The Bouguer gravity anomaly increases rapidly from $122^{\circ} \mathrm{E}$ to the WPB, where the Bouguer anomaly reaches values near +400 mgal . This may be due to the transition from island arc to oceanic crust. The free-air gravity anomalies in the WPB are small, in the range of about $20 \mathrm{mgal}$ or less. The low anomaly is closely associated with the variations in seabed topography. The region between $123-133^{\circ} \mathrm{E}$ shows a manifest positive Bouguer anomaly accompanied by a small scale free-air gravity anomaly (Fig. 5). It is most likely caused by an upwelling of high-density mantle material beneath the WPB to compensate for the mass deficiency in seawater and sediments. This indicates that the WPB is nearly isostatically compensated.

The Bouguer gravity anomaly of the PKR reduces to 300 mgal while the crustal thickness beneath the PKR 
increases to $13 \mathrm{~km}$. The crustal thickness beneath the PKR, which is a remnant arc created in the late Eocene, varies along the strike from 8 to approximately $20 \mathrm{~km}$. The crustal thickness in the PKR is greater than in its adjacent areas (Nishizawa et al. 2007). Further towards the east the freeair gravity anomaly has a near-zero value in the PVB. One expects the Bouguer anomaly to increase rapidly since it is known by seismic imaging that the crustal thickness is only $5 \mathrm{~km}$ beneath the PVB (Nishizawa et al. 2007). However, the Bouguer gravity anomaly increases slightly to $320 \mathrm{mgal}$. This somewhat incongruent result will be discussed using subsurface density modeling.

East of the cross-section the Bouguer anomalies are between 200 - 300 mgal in the MR, MTR, and the MIA. Lower Bouguer anomalies might imply that the crustal thickness decreases eastwards. It is interesting to note that the relatively thicker crustal peaks shift westward at a distance of $60 \mathrm{~km}$ from the axis of the MR and the MIA. The Mariana arc-trench system exhibits a large-amplitude free-air anomaly which is a typical characteristic of major subduction zones. The negative free-air anomaly of the MT having a value of $-150 \mathrm{mgal}$ is due to the presence of thick sediments. A positive free-air anomaly of about $100 \mathrm{mgal}$ is found in the MIA, about $200 \mathrm{~km}$ westward of the trench axis.

\subsection{Modeling of Subsurface Density Structure Along $15^{\circ} \mathrm{N}$}

By combining the results of this study, the petrological evidence of Ohara (2006) and the depth constraint between the lithosphere and asthenosphere interface obtained from Chang et al. (2007), we set up a 2D density model as shown in Fig. 6 to simulate the gravity anomaly along $15^{\circ} \mathrm{N}$. The gravity anomaly is perpendicular to the major structural trends, ranging from $125-147^{\circ} \mathrm{E}$. As described above, the Moho depth beneath the WPB is approximately $12 \mathrm{~km}$, and the crustal thickness of the PVB is about $5 \mathrm{~km}$. We assumed the top boundary of the asthenosphere is at depth of $38 \mathrm{~km}$ beneath the PVB and $50 \mathrm{~km}$ beneath the PKR. These values were inferred from Rayleigh wave dispersions (Chang et al. 2007). We also assumed the density of the asthenosphere is $3.25 \mathrm{~g} \mathrm{~cm}^{-3}$ (Yang et al. 1992). It is worth nothing that the density of the lithosphere beneath the PVB might be lighter than normal as Ohara (2006) pointed out that all of the collected peridotite samples from PVB were extensively serpentinized. The corresponding gravity anomaly of our density model was calculated using the method developed by Talwani et al. (1959). We found that our optimal model shown in Fig. 6 can fit the observed one remarkably well if we assume the lithosphere density under the PVB to be $3.25 \mathrm{~g} \mathrm{~cm}^{-3}$ (Fig. 6). This finding suggests that a relatively

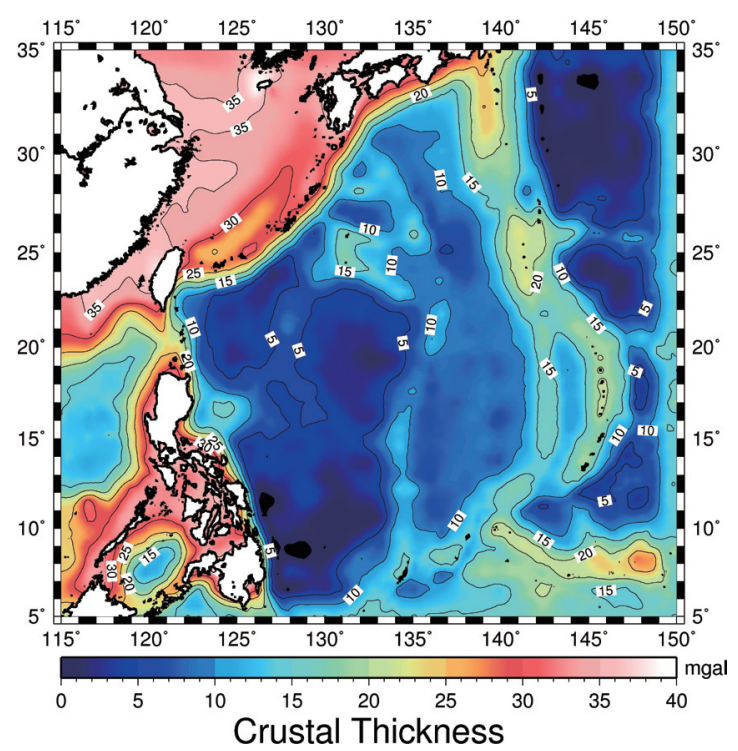

Fig. 4. Crustal thickness distribution in the PSP derived from the regional Bouguer gravity anomaly data. To avoid edge effects caused by the calculation process, the map is only shown for the range $7-33^{\circ} \mathrm{N}$ and $117-148^{\circ} \mathrm{E}$ (contour interval: $5 \mathrm{~km}$ ).

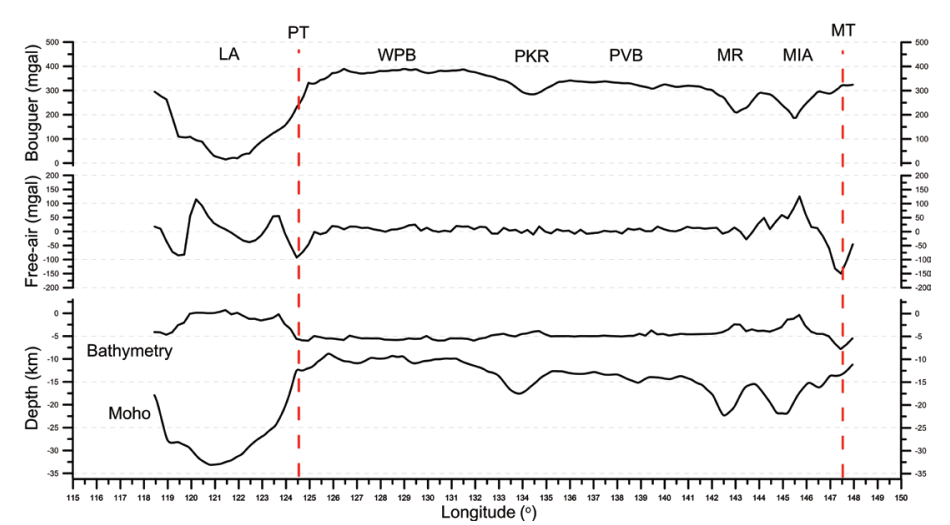

Fig. 5. The Bouguer and free-air gravity anomalies, the bathymetry and Moho depth along the profile drawn in Fig. 1. LA: Luzon Arc; PT: Philippine Trench; WPB: West Philippine Basin; PKR: Palau Kyushu Ridge; PVB: Parece Vela Basin; MR: Mariana Ridge; MT: Mariana Trench. The dashed line indicates the plate boundary. 


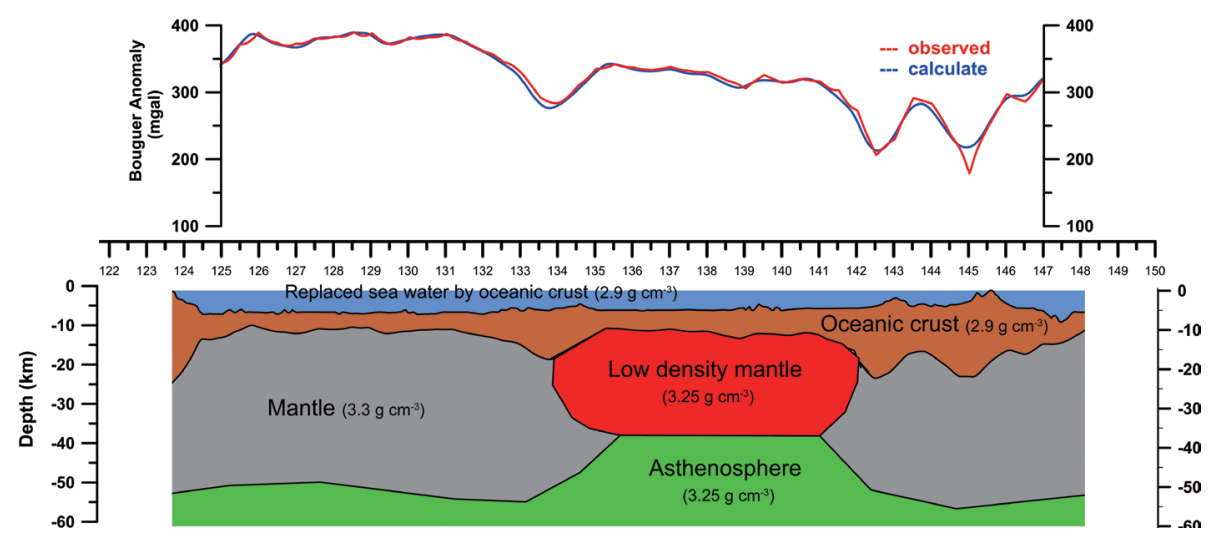

Fig. 6. A Bouguer gravity anomaly profile across the WPB, PKR, and PVB along $15^{\circ} \mathrm{N}$, ranging from $125-147^{\circ} \mathrm{E}$. The Bouguer anomaly calculated from the postulated density model fits the observed anomaly well. There is a relatively low density mantle and thinner lithosphere underneath the PVB. WPB: West Philippine Basin; PKR: Palau Kyushu Ridge; PVB: Parece Vela Basin.

thin and light (about 9\% serpentinization) lithosphere exists underneath the PVB. Both factors contribute to the relatively lower Bouguer gravity anomaly compared to that in the WPB and may result from active back-arc spreading. Although such a plausible density model is still far from being unique, it does provide a new insight into the thin oceanic crust, low-density oceanic mantle, and the upwardly convex asthenospheric structures under the PVB.

\section{CONCLUSIONS}

We compiled a free-air anomaly map for the PSP which shows that the gravity anomaly over the PSP generally has a low amplitude (in a range of $\pm 50 \mathrm{mgal}$ ) and long wavelength with near-zero average values. The isogals trend is generally consistent with the geological structures and closely correlates with the PSP bathymetry. The Bouguer anomaly map derived from the bathymetry and the free-air PSP anomaly has a value of $+300 \mathrm{mgal}$ or more over most parts of the PSP, while over the basins and island arcs on the PSP, the Bouguer gravity can be about 200 mgal smaller. The crustal thickness over the PSP is calculated from the regional Bouguer gravity anomaly.

The crustal thickness in the WPB is about $5 \mathrm{~km}$ on average with small variations, which implies that the WPB is quite stable. The low-amplitude and near-zero free-air gravity anomalies clearly indicate that the whole WPB, with the exception of trenches and island arcs, is nearly in a state of isostatic equilibrium. The PKR crustal thickness increases gradually from south to north, with an average value of more than $10 \mathrm{~km}$. The crustal thickness beneath the SB and PVB is smaller than $10 \mathrm{~km}$ overall. The thinnest crust, with a thickness of approximately $5 \mathrm{~km}$, is located in the southern part and at the western margin of the SB. In the eastern PSP the crustal thickness gradually increases eastward.

As there is no noticeable difference in the crustal thickness beneath the WPB and PVN based on seismic reflection studies, we proposed a simple density model, which suggests a thin and light lithosphere under the PVB. This relatively low density slab may be associated with the mantle peridotite serpentinization underneath the oceanic crust.

Acknowledgements The authors are grateful to the National Geophysical Data Center (NGDC) for providing the high quality gravity data. The authors would like to express their sincere appreciation to Prof. Wei-Hau Wang and the Anonymous Reviewer for critical reviews and excellent suggestions on this manuscript.

\section{REFERENCES}

Bowin, C., W. Warsi, and J. Milligan, 1982: Free-Air Gravity Anomaly Atlas of the World, Geological Society of America Map and Chart Series, No. MC-46, Woods Hole Oceanographic Institution, 190 pp.

Chang, W. Y., G. K. Yu, R. D. Hwang, and J. K. Chiu, 2007: Lateral variations of Rayleigh-wave dispersions in the Philippine Sea region. Terr. Atmos. Ocean. Sci., 18, 859-878, doi: 10.3319/TAO.2007.18.5.859(T). [Link]

Fujioka, K., K. Okino, T. Kanamatsu, Y. Ohara, O. Ishizuka, S. Haraguchi, and T. Ishii, 1999: Enigmatic extinct spreading center in the West Philippine backarc basin unveiled. Geology, 27, 1135-1138, doi: 10.1130/0091-7613(1999)027<1135:EESCIT>2.3.CO;2. [Link]

Gómez-Ortiz, D. and B. N. P. Agarwal, 2005: 3DINVER.M: A MATLAB program to invert the gravity anomaly over a 3D horizontal density interface by Parker-Oldenburg's algorithm. Comput. Geosci., 31, 513-520, doi: 10.1016/j.cageo.2004.11.004. [Link]

Hall, R., J. R. Ali, C. D. Anderson, and S. J. Baker, 1995: Origin and motion history of the Philippine Sea Plate. Tectonophysics, 251, 229-250, doi: 10.1016/00401951(95)00038-0. [Link] 
Ishihara, T. and K. Koda, 2007: Variation of crustal thickness in the Philippine Sea deduced from three-dimensional gravity modeling. Isl. Arc, 16, 322-337, doi: 10.1111/j.1440-1738.2007.00593.x. [Link]

Isse, T., H. Shiobara, Y. Tamura, D. Suetsugu, K. Yoshizawa, H. Sugioka, A. Ito, T. Kanazawa, M. Shinohara, K. Mochizuki, E. Araki, K. Nakahigashi, H. Kawakatsu, A. Shito, Y. Fukao, O. Ishizuka, and J. B. Gill, 2009: Seismic structure of the upper mantle beneath the Philippine Sea from seafloor and land observation: Implications for mantle convection and magma genesis in the Izu-BoninMariana subduction zone. Earth Planet. Sci. Lett., 278, 107-119, doi: 10.1016/j.epsl.2008.11.032. [Link]

Kamimura, A., J. Kasahara, M. Shinohara, R. Hino, H. Shiobara, G. Fujie, and T. Kanazawa, 2002: Crustal structure study at the Izu-Bonin subduction zone around $31^{\circ} \mathrm{N}$ : Implications of serpentinized materials along the subduction plate boundary. Phys. Earth Planet. Inter., 132, 105-129, doi: 10.1016/S0031-9201(02)00047-X. [Link]

Kodaira, S., T. Sato, N. Takahashi, S. Miura, Y. Tamura, Y. Tatsumi, and Y. Kaneda, 2007: New seismological constraints on growth of continental crust in the IzuBonin intra-oceanic arc. Geology, 35, 1031-1034, doi: 10.1130/G23901A.1. [Link]

Lowrie, W., 2007: Fundamentals of Geophysics, $2^{\text {nd }}$ edition, Cambridge University Press, New York, 390 pp.

Martyshko, P. S. and I. L. Prutkin, 2003: Technology of depth distribution of gravity field sources. Geophys. J., 25, 159-168. (in Russian)

Mooney, W. D., G. Laske, and T. G. Masters, 1998: CRUST 5.1: A global crustal model at $5^{\circ} \times 5^{\circ}$.J. Geophys. Res., 103, 727-747, doi: 10.1029/97JB02122. [Link]

Nakamura, Y. and T. Shibutani, 1998: Three-dimensional shear wave velocity structure in the upper mantle beneath the Philippine Sea region. Earth Planets Space, 50, 939-952, doi: 10.1186/BF03352189. [Link]

Nishizawa, A., K. Kaneda, Y. Katagiri, and J. Kasahara, 2007: Variation in crustal structure along the KyushuPalau Ridge at $15-21^{\circ} \mathrm{N}$ on the Philippine Sea plate based on seismic refraction profiles. Earth Planets Space, 59, e17-e20, doi: 10.1186/BF03352711. [Link]

Nishizawa, A., K. Kaneda, and M. Oikawa, 2011: Backarc basin oceanic crust and uppermost mantle seismic velocity structure of the Shikoku Basin, south of Japan. Earth Planets Space, 63, 151-155, doi: 10.5047/ eps.2010.12.003. [Link]

Oda, H. and N. Senna, 1994: Regional variation in surface wave group velocities in the Philippine Sea. Tectonophysics, 233, 265-277, doi: 10.1016/00401951(94)90245-3. [Link]

Ohara, Y., 2006: Mantle process beneath Philippine Sea back-arc spreading ridges: A synthesis of peridotite petrology and tectonics. Isl. Arc, 15, 119-129, doi: 10.1111/j.1440-1738.2006.00515.x. [Link]
Okino, K. and K. Fujioka, 2003: The Central Basin Spreading Center in the Philippine Sea: Structure of an extinct spreading center and implications for marginal basin formation. J. Geophys. Res., 108, doi: 10.1029/2001JB001095. [Link]

Okino, K., S. Kasuga, and Y. Ohara, 1998: A new scenario of the Parece Vela Basin genesis. Mar. Geophys. Res., 20, 21-40, doi: 10.1023/A:1004377422118. [Link]

Okino, K., Y. Ohara, S. Kasuga, and Y. Kato, 1999: The Philippine Sea: New survey results reveal the structure and the history of the marginal basins. Geophys. Res. Lett., 26, 2287-2290, doi: 10.1029/1999GL900537. [Link]

Oldenburg, D. W., 1974: The inversion and interpretation of gravity anomalies. Geophysics, 39, 526-536, doi: 10.1190/1.1440444. [Link]

Parker, R.L., 1973: The rapid calculation of potential anomalies. Geophys. J. Int., 31, 447-455, doi: 10.1111/j.1365246X.1973.tb06513.x. [Link]

Seekins, L. C. and T. Teng, 1977: Lateral variations in the structure of the Philippine Sea Plate. J. Geophys. Res., 82, 317-324, doi: 10.1029/JB082i002p00317. [Link]

Seno, T. and S. Maruyama, 1984: Paleogeographic reconstruction and origin of the Philippine Sea. Tectonophysics, 102, 53-84, doi: 10.1016/0040-1951(84)90008-8. [Link]

Talwani, M., J. L. Worzel, and M. Landisman, 1959: Rapid gravity computations for two-dimensional bodies with application to the Mendocino submarine fracture zone. J. Geophys. Res., 64, 49-59, doi: 10.1029/ JZ064i001p00049. [Link]

Vasin, V. V., I. L. Prutkin, and L. Y. Timerkhanova, 1996: Retrieval of a three-dimensional relief of geological boundary from gravity data. Izv.-Phys. Solid Earth, 32, 901-905.

Yang, C. S., J. Segawa, and Y. Fukuda, 1992: Density structure of the Mariana Arc and its vicinity obtained from successive inversion of the gravity anomaly. Tectonophysics, 206, 325-339, doi: 10.1016/00401951(92)90384-I. [Link]

Yang, Y. S. and T. K. Wang, 1998: Crustal velocity variation of the western Philippine Sea Plate from TAICRUST OBS/MCS line 23. Terr. Atmos. Ocean. Sci., 9, 379-393.

Yeh, Y. L., H. Kao, S. Wen, W. Y. Chang, and C. H. Chen, 2013: Surface wave tomography and azimuthal anisotropy of the Philippine Sea Plate. Tectonophysics, 592, 94-112, doi: 10.1016/j.tecto.2013.02.005. [Link]

Yu, G. K. and W. Y. Chang, 1991: Lateral variations in upper mantle structure of the Philippine Sea basin. Terr. Atmos. Ocean. Sci., 2, 281-296.

Yu, G. K., M. T. Tsai, and R. D. Hwang, 2000: Velocity dispersion and amplitude attenuation of Rayleigh waves across the Philippine Sea.Terr. Atmos. Ocean.Sci., 11, 515-524. 